\title{
Perfil epidemiológico de doadores de sangue soropositivos para Doença de Chagas na Região Sul
}

\author{
Juliana Pivetta Cogo ${ }^{1}$ Aline Foletto ${ }^{2}$ Janete Bolzan Monteiro ${ }^{3}$ Karla Nunes Pereira ${ }^{4}$ Marinei Cristina Pereira Ribeiro ${ }^{5}$ Zanoni \\ Segala ${ }^{6}$ Fallon Siqueira ${ }^{7}$ Sandra Trevisan Beck ${ }^{8}$
}

\begin{abstract}
RESUMO
0 presente estudo teve como objetivo conhecer o perfil epidemiológico dos doadores soropositivos para Doença de Chagas. Foram analisados os resultados da triagem sorológica de 25.207 doações no período de janeiro de 2004 a dezembro de 2007 no Serviço de Hemoterapia (SHT) do Hospital Universitário de Santa Maria (HUSM). Daqueles indivíduos que apresentaram resultado sorológico para Doença de Chagas, reagente ou indeterminado , foram avaliados retrospectivamente através dos dados obtidos através da entrevista prévia à doação. Entre os candidatos a doação com sorologia reagente para Trypanosoma cruzi (T.cruzi), $72,76 \%$ eram do sexo masculino com idade superior a 30 anos. Considerando o aspecto referente ao nascimento e residência, 36,99\% das doações foram realizadas por indivíduos com suspeita sorológica para Doença de Chagas, nascidos e residentes em municípios da região considerados fora de risco para esta infecção. A prevalência de sorologia reagente ou com resultado indeterminado para Doença de Chagas foi de $0,98 \%$. A frequencia de descarte de hemocomponentes ocorreu devido sorologia reagente $(63,01 \%)$ ou resultado indeterminado $(36,99 \%)$. 0 desenvolvimento de testes mais específicos poderá vir a evitar a exclusão de um doador de sangue em potencial.
\end{abstract}

Descritores: Doença de Chagas; Epidemiologia; Sorologia.

\section{Epidemiological profile of blood donors seropositive for Chagas disease in the Southern Region}

\begin{abstract}
The present study aimed to assess the epidemiological profile of seropositive donors for Chagas' disease. We analyzed the results of serological screening of 25.207 donations from January 2004 to December 2007 at the Service of Hematology (SHT) of the University Hospital of Santa Maria (HUSM). Those individuals who had serologic results for Chagas disease, reagent or undetermined, were evaluated retrospectively using data obtained according to the interviews prior to donation. Among the candidates for donation with reagent serology for Trypanosoma cruzi (T. cruzi), $72.76 \%$ were males aged over 30 years old. Considering the aspect regarding the birth and residence, $36.99 \%$ of the donations were made by individuals with suspected serology for Chagas Disease, born and living in cities outside the region considered at risk for this infection. The prevalence of positive or indeterminate serology for Chagas disease was $0.98 \%$. Discharge of blood components was due reagent serology $(63.01 \%)$ or indeterminate results $(36.99 \%)$. Developments of more specific tests are likely to avoid the exclusion of a potential blood donor.
\end{abstract}

Descriptors: Chagas Disease; Epidemiology; Serology.

\footnotetext{
${ }^{1}$ Mestre em Química analítica pela Universidade Federal de Santa Maria, (UFSM), Santa Maria, RS, Brasil.

${ }^{2}$ Especialista em Análises clínicas pela Universidade de Santa Cruz do Sul, (UNISC), Santa Cruz, RS, Brasil.

${ }^{3}$ Arquivista pela Universidade Federal de Santa Maria (UFSM), Santa Maria, RS, Brasil.

${ }^{4}$ Mestre em Ciências Farmacêuticas pela Universidade Federal de Santa Maria (UFSM), Santa Maria, RS, Brasil.

${ }^{5}$ Doutora em Bioquímica pela Universidade Federal do Rio Grande do Sul (UFRGS), Porto Alegre, RS, Brasil.

${ }^{6}$ Especialista em Hemoterapia pela Universidade Federal do Rio Grande do Sul (UFRGS), Porto Alegre, RS, Brasil.

${ }^{7}$ Graduando de Farmácia na Universidade Federal de Santa Maria (UFSM), Santa Maria, RS, Brasil.

${ }^{8}$ Doutora em Farmácia pela Universidade de São Paulo (USP), São Paulo, SP, Brasil.
} 


\section{Introdução}

A Doença de Chagas é ainda um dos maiores problemas de saúde pública na área rural e urbana da América Central e América do Sul, onde 16 a 18 milhões de pessoas são infectadas, com aproximadamente 300.000 novos casos por ano. ${ }^{1}$ A doença é causada pelo protozoário Trypanosoma cruzi (T.cruzi), que é transmitido, principalmente pelas fezes de vetores (Triatomas sp) infectados. ${ }^{2}$ No Brasil as principais espécies são: Triatoma infestans, Panstrongylus megistus, Triatoma brasiliensis, Triatoma pseudomaculata, Triatoma vitticeps e Triatoma sordida. Essa diversidade de vetores capazes de transmitir a doença de Chagas dificulta a erradicação da doença através da eliminação dos vetores. ${ }^{3}$

Enquanto a transmissão clássica é controlada por programas sanitários para erradicar os vetores nas áreas endêmicas, a transfusão de sangue precisa ser muito bem controlada para impedir a transmissão por esta via, principalmente nas áreas urbanas. Vários indivíduos que se encontram na fase crônica são assintomáticos, assim a transmissão pode ocorrer por intermédio de hemocomponentes oriundos de doadores infectados que desconhecem a existência dessa infecção. ${ }^{4}$

A infectividade do componente sangüíneo depende da cepa do parasita, da parasitemia na hora da doação, do estado imunológico do receptor, do número de transfusões e do volume de sangue transfundido. ${ }^{5} \mathrm{O}$ protozoário T. cruzi permanece viável e virulento por duas a três semanas no sangue armazenado em refrigerador, seja no plasma ou papa de hemácias. ${ }^{6}$ Em amostras coletadas com anticoagulante citrato, à temperatura ambiente, o parasita permanece viável por mais de 250 dias. $^{5}$

As investigações sorológicas realizadas em doadores de sangue na América do Sul têm revelado uma taxa variável de resultados soropositivos (0,2-28\%) para $T$. cruzi e, conseqüentemente do potencial para infectar receptores de sangue. ${ }^{4}$ Além disso, o trabalho de Lunardelli et al $(2007)^{7}$ mostra que o risco de transmissão da infecção via transfusão de sangue contaminado é de cerca de $12 \%-25 \%$.

Conseqüentemente, o desafio dos Serviços de Hemoterapia (Bancos de Sangue) está em identificar e excluir portadores assintomáticos crônicos do parasita sem prejudicar o estoque de hemocomponentes. ${ }^{8} \mathrm{~A}$ transfusão de sangue é considerada a segunda via de transmissão mais frequente e a principal via em países industrializados de baixa endemicidade para a Doença de Chagas, principalmente aqueles que recebem fluxos migratórios significativos de pessoas provenientes dos países da América Latina. ${ }^{9}$

Nos países onde a Doença de Chagas é endêmica, é realizado o rastreio de anticorpos contra o $T$. cruzi em todos os doadores de sangue. A soroprevalência da infecção em doadores varia entre $0.3 \%$ (Nicarágua) e 15\% (Bolívia). ${ }^{10}$ No entanto, este risco pode ser ainda menor; pois nos EUA, mostrou-se que onze pessoas que tinham recebido hemocomponentes com sorologia positiva para T. cruzi permaneceram soronegativos. ${ }^{8}$

Apesar das normas que regulamentam a hemoterapia, pouco se sabe ainda sobre a realidade hemoterápica na América Latina, sendo a transfusão sangüínea considerada ainda como um dos principais meios de transmissão da Doença de Chagas. A instituição de programas de erradicação do vetor e de controle da transmissão por via transfusional, como a Iniciativa do Cone Sul desenvolvida pela Organização de Saúde Pan-Americana, tem permitido diminuir a incidência da infecção nestes países e diminuir o risco de transmissão da doença por transfusão. ${ }^{11}$

O presente estudo teve como objetivo determinar a soroprevalência e o perfil dos indivíduos com Doença de Chagas entre os doadores de sangue no Hospital Universitário de Santa Maria.

\section{Materiais e Métodos}

Foi realizado um estudo descritivo, transversal, retrospectivo dos resultados da triagem sorológica e dados obtidos durante a entrevista pré-doação de sangue, de 25.207 doações realizadas entre janeiro de 2004 a dezembro de 2007 no Serviço de Hemoterapia do HUSM.

A partir dos resultados sorológicos registrados em banco de dados, foram selecionados os doadores de sangue com sorologia reagente ou indeterminada para Doença de Chagas. Nesse grupo foi realizada a avaliação do perfil epidemiológico de acordo com os dados apresentados no cadastro de cada doador.

As amostras de sangue colhidas dos doadores de sangue do SHT/HUSM foram submetidas à análise sorológica conforme a legislação em vigor, utilizando reagentes comerciais padronizados e validados para uso na triagem sorológica 
das seguintes patologias: Doença de Chagas (Wiener lab.); HIV I/II (Biorad, Dade Behring, Biomérieux), HTLV I/II (Diasorin Murex, Biomérieux), Hepatite B e Hepatite C (Diasorin, Biomérieux, Wiener lab., Biorad) e Sífilis (Wiener lab.). Os testes sorológicos realizados através do método imunoenzimatico (ELISA) apresentam alta sensibilidade e especificidade, conforme o preconizado pela ANVISA. Os resultados destas sorologias foram analisados a partir do registro de doadores mantido no setor de hemoterapia.

O estudo foi aprovado pelo Comitê de Ética em Pesquisa da Universidade Federal de Santa Maria sob o CAAE 0260.0.243.000-08

Os dados foram analisados através de estatística descritiva.

\section{Resultados}

Entre as 25.207 doações realizadas, $246(0,98 \%)$ apresentaram sorologia reagente ou indeterminada para a Doença de Chagas, o que resultou no descarte de seus hemocomponentes.

Entre os hemocomponentes descartados pelo risco de transmissão de Doença de Chagas, $63 \%$ apresentaram sorologia reagente e $37 \%$ resultado sorológico indeterminado. Os índices de prevalência sorológica com resultado reagente ou indeterminado, nos anos de 2004, 2005, 2006 e 2007, mostram que com o passar dos anos os resultados indeterminados diminuíram discretamente (Tabela 1).

Tabela 1 - Prevalência de sorologia reagente ou indeterminada para Doença de Chagas em candidatos a doadores de sangue atendidos no Serviço de Hemoterapia do HUSM, no período de janeiro de 2004 a dezembro de 2007.

\begin{tabular}{c|c|c|c}
\hline Ano & $\begin{array}{c}\text { Doadores } \\
\left(\mathrm{N}^{0}\right)\end{array}$ & $\begin{array}{c}\text { Sorologia } \\
\left(\mathrm{N}^{0}\right)\end{array}$ & $\begin{array}{c}\text { Reagente ou } \\
\text { Indeterminada } \\
(\%)\end{array}$ \\
\hline 2004 & 7054 & 88 & 1,25 \\
\hline 2005 & 6053 & 59 & 0,97 \\
\hline 2006 & 6084 & 50 & 0,82 \\
\hline 2007 & 6016 & 49 & 0,81 \\
\hline Total & 25.207 & 246 & 0,98 \\
\hline
\end{tabular}

Entre os candidatos a doadores que apresentaram sorologia positiva para anticorpos anti- $T$. cruzi observou-se prevalência do sexo masculino (72,26\%). Aproximadamente $80 \%$ dos doadores, independente do sexo, encontravam-se na faixa etária igual ou superior a 30 anos (Tabela 2).

Tabela 2 - Distribuição dos candidatos a doadores de sangue com sorologia positiva para Trypanosoma cruzi atendidos no Serviço de Hemoterapia do HUSM, no período de janeiro de 2004 a dezembro de 2007, segundo a faixa etária.

\begin{tabular}{c|c|c}
\hline \multirow{2}{*}{ Faixa etária } & $\left(\mathrm{N}^{\circ}\right)$ & $(\%)$ \\
\cline { 2 - 3 } & 46 & 18,70 \\
\hline$<30$ anos & 200 & 81,30 \\
\hline$\geq 30$ anos & 246 & 100 \\
\hline Total & & \multicolumn{2}{c}{ Candidatos a doadores com sorologia positiva } \\
\hline
\end{tabular}

A naturalidade e residência dos doadores com resultado de sorologia reagente ou indeterminada é diversa, sendo estes indivíduos oriundos de diferentes municípios do Rio Grande do Sul. Baseado nos indicadores de análise do grau de risco para Doenças de Chagas (entomológicos,ambientais e demográficos), os municípios são estratificados em municípios em alto, médio e baixo risco para a Doença de Chagas $^{12}$. No presente estudo os doadores referiram ser natural ou residir em 65 diferentes cidades do RGS. Entre estes, 24 municípios não estão classificados dentro dos critérios de risco, sendo considerados fora de risco para contaminação vetorial para a Doença de Chagas. Apenas 4 municípios são considerados de alto risco; 19 municípios com médio risco e 18 municípios com baixo risco. Apenas 6\% dos doadores com reação sorológica positiva ou indeterminado para Doença de Chagas residiam ou eram naturais das cidades classificadas como alto risco (Figura 1). 


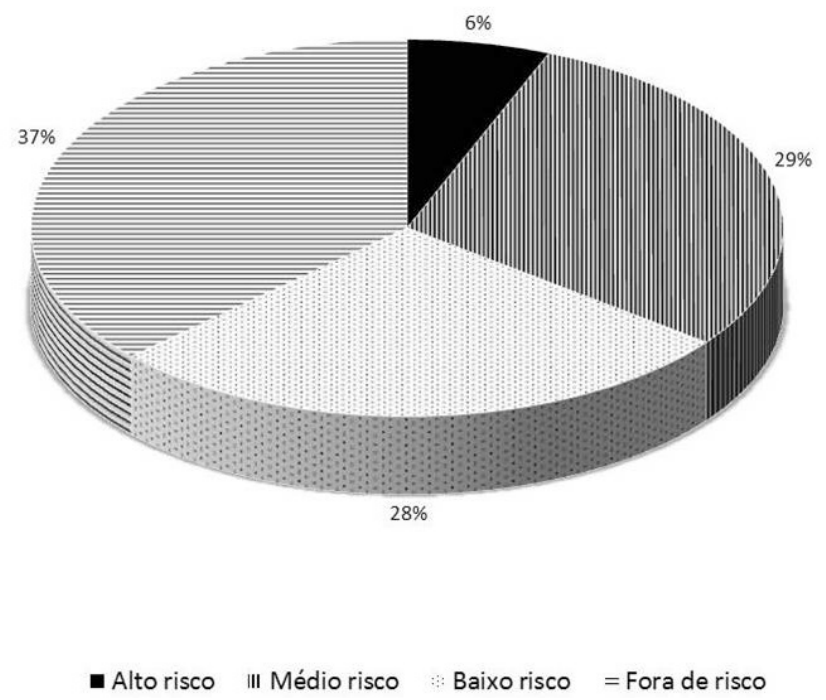

Figura 1 - Distribuição dos doadores de sangue sororeagentes ou indeterminados conforme a naturalidade e/ou residência de acordo com a área de risco.

\section{Discussão}

Os dados epidemiológicos e entomológicos apresentados pelo Ministério da Saúde do Brasil na nona reunião da Comissão Intergovernamental da Iniciativa do Cone Sul (realizada no Rio de Janeiro em Março de 2000) confirmou que 10 dos 12 estados endêmicos no Brasil foram considerados livres de transmissão vertical da doença de Chagas. 0 total dos 10 estados são: Goiás, Mato Grosso, Mato Grosso do Sul, Minas Gerais, Paraíba, Pernambuco, Piauí, Rio de Janeiro, Rio Grande do Sul e São Paulo. Os outros dois estados são Bahia e Tocantins. . $^{13,14}$ Sabendo-se disso em 2006, 0 Brasil foi certificado como livre área da doença de Chagas transmissão vetorial pelo Pan-Americana Organização Mundial da Saúde (OPAS), no entanto, isso representou a temporária interrupção da doença especificamente pelo triatomídeos de espécies de $T$. infestans e não a sua erradicação. ${ }^{15}$ Outras espécies de triatomíneos têm sido associadas com a transmissão de $T$. cruzi em meios rural e periurbano. Além disso, vias de transmissão independentes de vetores, como a via oral, têm sido descritas na última década. ${ }^{16}$

Após a interrupção completa ou parcial da transmissão através de vetor a transfusão de sangue tornou-se o principal mecanismo de aquisição da doença de Chagas na década de 1980 e 1990. A partir da Constituição de 1988, novos mecanismos foram criados para evitar a transmissão de várias doenças por transfusão de sangue, entre os quais o HIV e doença de Chagas. A remuneração de doadores foi proibida, e a triagem sorológica de candidatos à doação de sangue tornou-se obrigatória. ${ }^{17}$

A entrevista realizada durante a triagem clínica, no Serviço de Hemoterapia, é de fundamental importância para discriminar doadores com risco de apresentarem infecção pelo T. cruzi. Aanálise sorológica para pesquisa de anticorpos contra este protozoário é realizada através de técnicas padronizadas para diagnóstico, apresentando especificidade e sensibilidade próxima a 99\%, uma vez que utiliza para a detecção dos anticorpos, antígenos recombinantes e purificados de T. cruzi. Isto pode diminuir as infecções relacionadas à transmissão por transfusão sangüínea na população não exposta à transmissão vetorial dessa zoonose. ${ }^{6}$

A prevalência de sorologia reagente ou indeterminada para a Doença de Chagas de 0,98\% (Tabela 1), foi superior a outros Serviços de Hemoterapia, como demonstram os estudos realizados no Serviço de Hemoterapia de Porto Alegre e no HEMOPEL de Pelotas, os quais apresentam prevalências de $0,4 \%$ e 0,5\%, respectivamente, no ano de $2007 .{ }^{7}$

Analisando-se a evolução ano a ano, da prevalência de sorologia positiva para $T$. cruzi entre os candidatos à doação no SHT do HUSM verificou-se que no ano de 2004, o índice de descarte registrado foi superior aos anos seguintes analisados. Este fato foi demonstrado pela prevalência de 1,25\% de amostras soropositivas para T. cruzi no ano de 2004 e 0,97, 0,82 e 0,81\% nos anos de 2005, 2006 e 2007, respectivamente, na comunidade analisada. 
Esses resultados podem estar associados à qualidade técnica dos testes utilizados, uma vez que o SHT do HUSM até junho de 2004 utilizava métodos de Enzimaimunoensaio (ELISA) e gel-centrifugação para determinação da sorologia para Doença de Chagas e, no momento em que começou vigorar a RDC 153 de $2004^{18}$, passou a utilizar somente 0 método de ELISA, o que pode explicar a diminuição nos resultados positivos para a Doença de Chagas, pela melhor especificidade do novo teste. De fato, quando os métodos de triagem apresentavam resultados discordantes, a bolsa era descartada, uma vez que a lei em vigor não exigia a realização de testes confirmatórios por parte do SHT. A partir do momento em que o SHT passou a utilizar apenas uma técnica sorológica (ELISA) houve uma diminuição no número de descartes de bolsas, pelo motivo de não haver discordância entre os métodos.

A análise dos dados em relação ao índice de descarte de hemocomponentes revelou um elevado percentual (36,99\%) de hemocomponentes descartados por resultados sorológicos indeterminados, fato que pode comprometer a disponibilidade de hemocomponentes do Serviço de Hemoterapia, além de vir a impedir futuras doações. Nesse contexto, tem sido pesquisado, arduamente, proposições de novos tipos de testes laboratoriais em especial relacionados com a qualidade dos antígenos (geralmente proteínas do T.cruzi) e de metodologias, visando melhorar parâmetros como sensibilidade e especificidade do teste e execução de um método mais simples e com menor custo. ${ }^{19}$ Outras técnicas capazes de verificar a presença de $T$. cruzi em pacientes infectados incluem hemocultura, xenodiagnóstico e PCR. ${ }^{20}$

Observou-se que, entre os doadores com menos de 30 anos de idade, uma porcentagem pequena (18,70\%) eram soropositivos para Doença de Chagas. A grande maioria (81,30\%) dos inaptos sorológicos apresentavam idade igual ou superior a 30 anos. Este resultado era esperado uma vez que os programas de controle nacional do vetor da doença de Chagas iniciaram nos anos 70 , ocasião em que surgiram as primeiras regulamentações específicas para doação de sangue no País. ${ }^{21} \mathrm{~A}$ menor prevalência de inaptidão sorológica para doença de Chagas em indivíduos mais jovens, ou seja, menores de 30 anos, corresponde ao período de introdução das medidas de controle da transmissão vetorial da doença em nossa região e, nos últimos vinte anos, aos programas de recrutamento, seleção e fidelização, com evidente mudança do perfil dos doadores do HUSM.

Nesse estudo os doadores com sorologia reagente ou indeterminada para Doença de Chagas foram provenientes de 65 municípios do Rio Grande do Sul, predominando doadores de Santa Maria, São Francisco de Assis e São Pedro do Sul. Portanto, um fato importante apresentado nesse estudo é que 36,99\% das doações soropositivas foram realizadas por indivíduos que nasceram e continuam residindo em municípios considerados como fora de risco para transmissão vetorial.

Porem, a transmissão tanto oral, como congênita, constitui uma via, em potencial, de manutenção da endemia chagásica no Brasil. Assim, é recomendável tornar rotineira a investigação de gestantes chagásicas no pré-natal e garantir o tratamento de recém-nascidos infectados. ${ }^{22}$ Estas vias de transmissão encontram-se bem documentadas, com relatos de casos, como o descrito por Pinto et $a^{23}$ (2011), onde uma família composta por quatro pessoas, foram contaminadas pela forma oral (consumo de açaí) sendo uma delas mulher, com 12 semanas de gestação. A infecção foi confirmada por métodos parasitológicos (cultura de T. cruzi) e sorológicamente através da pesquisa de anticorpos anti T. cruzi, e a gestante acompanhada durante toda a sua gestação. Dois dias após o nascimento, o recém nascido foi submetido a exames parasitológicos e sorológicos visando à detecção de infecção por $T$. Cruzi que resultaram negativo. Contudo, após o quarto mês foi observada uma conversão sorológica positiva (aparecimento de anticorpos anti-T. cruzi), confirmando a infecção congênita. ${ }^{23}$

\section{Considerações finais}

Após a avaliação dos dados epidemiológicos dos candidatos à doação de sangue do Serviço de Hemoterapia do HUSM pode-se concluir que as sorologias reagentes ou indeterminadas correspondem em sua maioria a candidatos à doação do sexo masculino e com idade igual ou superior a 30 anos, podendo estes indivíduos ter adquirido a doença em um período em que os testes sorológicos não eram tão eficiente para o controle da transmissão sanguínea, ou antes da erradicação do principal vetor transmissor. Com relação ao local de nascimento e a residência foram cadastrados doadores de cidades de alto, médio e baixo risco, como também de regiões consideradas fora da área de risco. Desta forma podemos inferir que, apesar do avanço no controle da doença e nos métodos diagnósticos, a erradicação da Doença de Chagas ainda é uma meta a ser atingida, devido às outras formas de transmissão que tem se apresentado 
(forma oral e congênita). Também se faz necessário o desenvolvimento de testes laboratoriais cada vez mais específicos para detecção da Doença de Chagas que garantam a segurança transfusional sem prejudicar os estoques de hemocomponentes devido a resultados indeterminados.

\section{Referências bibliográficas}

1. Dutra WO, Rocha MOC, Teixeira MM. The clinical immunology of human chagas disease. Trends Parasitol. 2005;21:581-7. 2. Bestetti RB, Muccillo G. Clinical Course Of Chagas" heart disease: a comparison with dilated cardiomyopathy. Int J Cardiol. 1997;60:187-93.

3. Silveira AC, Dias JCP. O controle da transmissão vetorial. Rev Soc Bras Med Trop. 2011;44(2):52-63.

4. Kirchhoff LV, Paredes P, Lomelí-Guerrero A, Paredes-Espinoza M, Ron-Guerrero CS, Delgado-Mejía M et al. Transfusion-associated Chagas disease (American trypanosomiasis) in Mexico: implications for transfusion medicine in the United States. Transfusion. 2006;46:298-304.

5. Wendel S, Dias JCP. Transfusion transmitted Chagas disease. In: Wendel S, Brener Z, Camargo ME, Rassia A. Chagas disease (American trypanosomiasis): its impact on transfusion and clinical medicine. 1992:103.

6. Gomes YM. PCR and sero-diagnosis in chronic Chagas'disease: biotechnological advances. Applied Biochemistry and Biotechnology 1997;66:107-119.

7. Lunardelli A, Borges FP, Mello KF, Zeferino ASA. Soroprevalência da doença de Chagas em candidatos a doadores de sangue. RBAC. 2007;39(2):139-41.

8. Blejer JL, Saguier MC, Salamone HJ. Antibodies to Trypanosoma cruzi among Blood Donors in Buenos Aires, Argentina. Int J Infect Dis. 2001;5:89-93.

9. Pereira BI, Nazareth C, Malcata L, Alves H, Fernández JR, Sargento C et al. Infecções parasitárias transmitidas por transfusão de sangue: qual o risco nos países não endémicos? Acta Med Port. 2011;24:897-906.

10. Dias JCP. Enfermedad de Chagas: epidemiologia y control. Enfermedades emergentes. 2005;7(1):11-18.

11. Organização Pan-Americana de Saúde (OPS). Iniciativa del Cono Sur: VI Renión Intergubernamental para la eiminación da Triatoma infestans y la interrupción de la tripanosomiasis americana por transfusion. Documento OPS/ HPC/HTC 98/102; 1997.

12. Áreas de Vigilância em Saúde Ambiental (DVAS) e Centro Estadual de Vigilância em Saúde (CEVS/SES). Porto Alegre; 2008.

13. WHO (World Health Organization). Brazil to be declared free of Chagas disease. TDR News. 2000;62:14.

14. WHO (World Health Organization). Chagas disease, Brazil-Interruption of transmission. Weekly Epidemiological Record. 2000;75:153-5.

15. Fitarelli $\mathrm{DB}$, Horn JF. Descarte de bolsas de sangue devido à reatividade para doença de Chagas em um laboratório de triagem sorológica de doadores em Porto Alegre-RS. Rev Bras Hematol Hemoter. 2009;31:310-4.

16. Mattos ER, Berto BP. Doença de Chagas: uma breve revisão das recentes ocorrências, vias de transmissão e métodos diagnósticos. Rev Saúde e Amb. 2011;6(2):40-5.

17. Dias JCP. Doença de Chagas e transfusão de sangue no Brasil: vigilância e desafios. Rev Bras Hematol Hemoter. 2006;28:83-4.

18. RDC 153, de 14 de junho de 2004. Disponível em: http://portal.anvisa.gov.br/wps/wcm/connect/4bc8428047457945865fd63fbc4c6735/ rdc_153.pd??MOD=AJPERES

19. Amato Neto V, De Marchi CR, Ferreira CS, Ferreira AW, De Marchi CR, Ferreira CS et al. Observações sobre o TESA blot no diagnóstico sorológico da doença de Chagas. Rev Soc Bras Med Trop. 2005;38:534-5.

20. Kinoshita-Yanaga AT, Bértoli M, Martins VA, Mizutani AS, Toledo MJO, Araújo SM et al. Polymerase chain reaction and blood culture in blood donors screened by ELISA test for Chagas' disease. Brazilian Journal of Pharmaceutical Sciences. 2011;47(1):53-61.

21. Dias JCP, Schofield CJ. Controle da transmissão transfusional da doença de Chagas na Iniciativa do Cone Sul. Rev Soc Bras Med Trop. 1998;31:373-83.

22. Silva TPT, Ferreira ILM. Eliminação da transmissão da doença de Chagas pelo Triatoma infestans no Brasil: um fato histórico. Rev Soc Bras Med Trop. 2006;39:507-9. 
23. Pinto AYN, Valente SAS, Valente VC, Figueiras ACM. Doença de Chagas congênita por infecção aguda maternal por Trypanosoma cruzi transmitida via oral. Rev Pan-Amaz Saude. 2011;2(1):89-94.

\section{Juliana Pivetta Cogo}

Endereço para correspondência - Rua Av. Liberdade, n.367. Bairro Passo d'Areia, CEP 97010-270, Santa Maria, RS, Brasil.

E-mail: julypiv@hotmail.com

Currículo Lattes: http://lattes.cnpq.br/1529117633972905

Aline Foletto - asffarm@gmail.com

Janete Bolzan Monteiro - jabolzan@yahoo.com.br

Karla Nunes Pereira - karlanunespereira@yahoo.com.br

Marinei Cristina Pereira Ribeiro - mcpribeiro@yahoo.com.br

Zanoni Segala - zanonisegala@gmail.com

Fallon Siqueira - fallon.farm@gmail.com

Sandra Trevisan Beck - sbeck@ig.com.br

Recebido em 22 de janeiro de 2013.

Publicado em 15 de maio de 2014. 
